F. Reprod. Fert. (1969) 19, 591-593

\title{
ASYNCHRONISM BETWEEN TUBAL AND UTERINE ACTIVITY IN WOMEN
}

\author{
E. M. COUTINHO AND H. DA SILVA MAIA \\ Department of Biochemistry and Obstetrics, Federal University of Bahia, Bahia, Brasil
}

(Received 25th March 1969)

Ovarian steroids are known to exert regulatory influences on human myometrial activity (Reynolds, 1949). In the non-pregnant uterus, both spontaneous activity and sensitivity to neurohypophysial hormones have been shown to be diminished by oestrogens and progesterone (Coutinho \& Lopes, 1968). In the latter study, uterine activity increased after withdrawal of oestrogens alone or after withdrawal of both oestrogen and progesterone. In both instances, the response of the myometrium to oxytocin or vasopressin was considerably exaggerated. During the ovulatory phase, no response could be elicited by these neurohypophysial hormones but during the luteal phase the uterus responded to vasopressin and remained refractory to oxytocin.

Extensive studies by the present authors and by other investigators (Moir, 1944; Hendricks, 1965; Coutinho, 1967) have dealt with the effects of ovarian steroids on the non-pregnant human uterus. On the other hand, comparatively few studies have been made to investigate the influences of these hormones on human tubal motility. No reliable records of tubal motility have been obtained during the menstrual cycle and for this reason the influence of ovarian activity upon the human tubes is unknown.

In order to determine if uterine contractions correlate with tubal motility and whether or not the peristaltic movements of the right and the left tubes are synchronous, it is necessary to record simultaneously the activity of the uterus and of both Fallopian tubes. Simultaneous recording became possible recently during a laparotomy for surgical correction of tubal obstruction. Complete details of the surgical technique have been described elsewhere (Maia \& Coutinho, 1968). In brief, a polyvinyl catheter, the intraluminal portion of which is fenestrated and sheathed by a thin rubber diaphragm, is inserted inside each Fallopian tube. The end of the catheter is sealed by heat and by a nylon suture, which is anchored to the uterine fundus with a suture of chromic catgut. The free ends of the two catheters are brought to the outside through $1-\mathrm{cm}$ incisions in the corresponding side of the abdominal wall and are held in place with adhesive tape. The rubber-covered, fenestrated portion of the catheter acts as the receptor for the pressure changes occurring in the lumen of the tube. To record tubal activity, the external end of each tube is connected to a pressure transducer (Sanborn $267 \mathrm{AC}$ ) and the signal is recorded in a Sanborn 321 Dual Channel Pre-Amplifier Recorder.

In order to record intra-uterine activity, a polyethylene catheter which is 
closed at one end by a small rubber balloon (capacity $0.5 \mathrm{ml}$ ) is introduced through the cervix into the endometrial cavity. The external end of the catheter is held in place on the medial aspect of the patient's thigh. Changes in intrauterine pressure are recorded on a 321 Sanborn Dual Channel Carrier PreAmplifier. Utilizing this technique, the patients have been recorded for many hours without discomfort. After each recording, the uterine receptor balloon is withdrawn, the external ends of the tubal catheters are disconnected from the

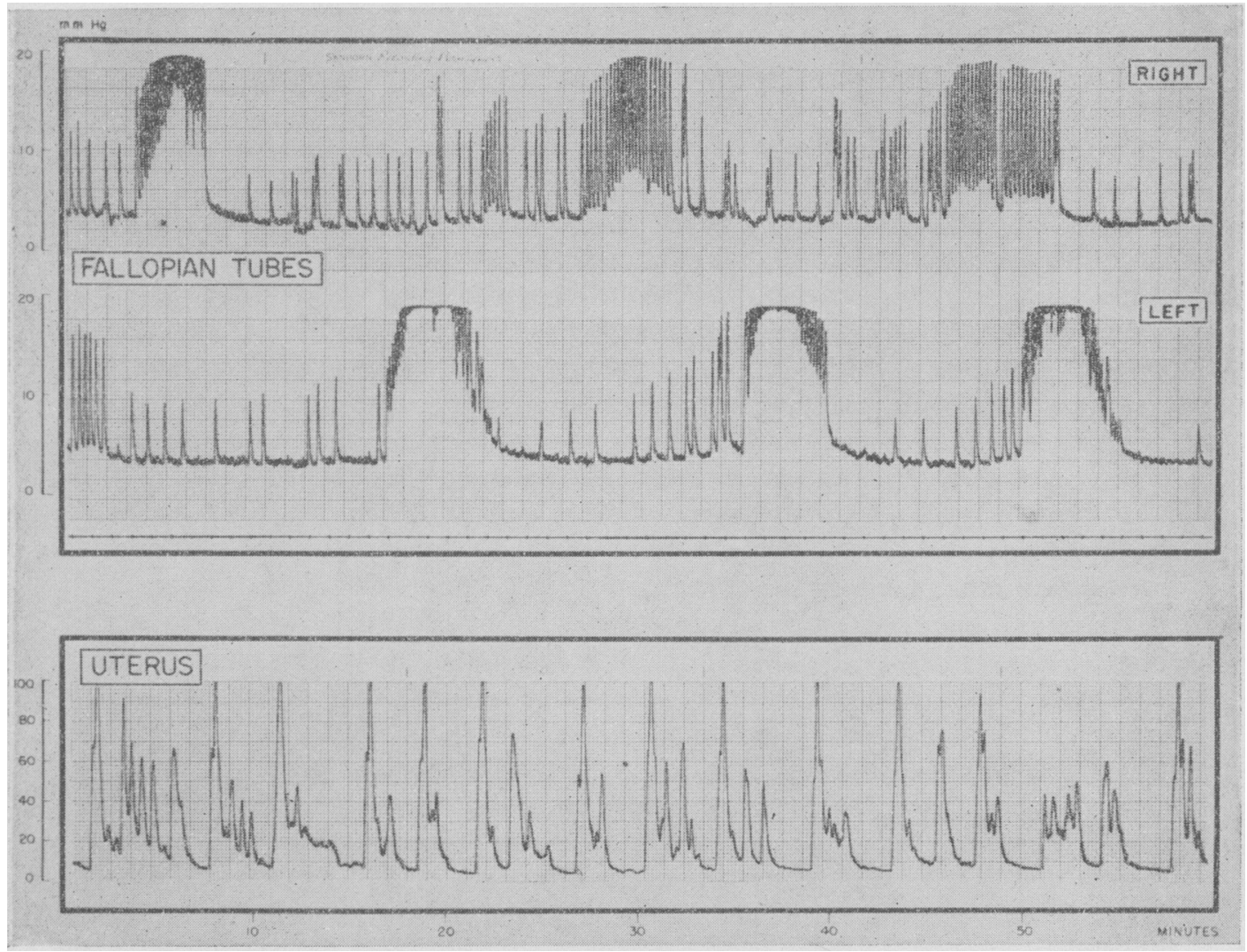

TExT-FIG. 1. Motility patterns of the uterus and Fallopian tubes of a 30-year-old woman on Day 2 of the menstrual cycle. Note the different scales for intra-tubal and intra-uterine pressures. Note that the intra-tubal pressures are not synchronous with one another nor is either of them synchronous with the intra-uterine pressure.

transducers and their tips sealed by burning and then attached to the skin of the patient with surgical adhesive tape.

The patients used in this study were infertile as a result of tubal occlusion from previous pelvic inflammatory disease. In each case, non-surgical attempts to effect tubal patency had failed. The surgical technique employed in this study is similar to that commonly used to restore tubal patency, namely the introduction of catheters through the Fallopian tubes and allowing them to remain in situ for 1 to 2 months (Coutinho, 1967). The most important change 
introduced by the authors was to convert the intraluminal portion of the catheter into a pressure receptor by fenestration of the catheter wall and by covering the fenestrated end with a rubber sheath. The results of these studies, of which only a small representative sample are included here, indicate that when the intraluminal pressures of both the tubes and of the uterus were recorded simultaneously, no relationship could be seen between the activity of the two tubes and that of the uterus. This lack of synchronism was noted in all phases of the menstrual cycle, but was particularly marked during menstruation when the spontaneous activity of both the uterus and the tubes was increased. These simultaneous pressure variations recorded over a period of $1 \mathrm{hr}$ are depicted in Text-fig. 1, where the typical activity of the tubes is shown side by side with that of the uterus of the same patient. It is apparent that (a) the tubal activity has a pattern of its own consisting of small contractions of approximately $5 \mathrm{~mm} \mathrm{Hg}$ pressure, and outbursts of greater activity which occur at regular intervals at which time the contractions reach $20 \mathrm{~mm} \mathrm{Hg}$ pressure, and (b) that peaks of activity of each tube bear no relationship with one another and are not synchronous, indicating that it is unlikely that they are caused by a systemic spurt of an endogenous stimulant such as oxytocin.

In summary, it appears that no synchronous relationship exists between the activity of either tube and that of the uterus.

The present study was supported by the Ford Foundation. The authors are grateful for the advice and help given by Professor H. Tatum in the preparation of the manuscript.

\section{REFERENCES}

Coutinho, E. M. (1967) Uterine activity in non-pregnant women. Proc. 8th Int. Conf. Int. Parenthood Fedn, p. 432. Eds. R. K. B. Hankinson, R. I. Kleinman and P. Eckstein. I.P.P.F., London.

Courinho, E. M. \& Lopes, A. C. V. (1968) Response of non-pregnant uterus to vasopressin as an index of ovarian function. Am. 7. Obstet. Gynec. 102, 479.

Hendricks, C. H. (1965) Activity patterns in the non-pregnant human uterus. In: Muscle, p. 349. Eds. W. M. Paul, E. E. Daniel, C. M. Kay and G. Monckton. Pergamon Press, London.

Maia, H. S. \& Coutinho, E. M. (1968) A new technique for recording human tubal activity in vivo. Am. 7. Obstet. Gynec. 102, 1043.

Morr, C. J. (1944) The effect of posterior lobe pituitary gland fractions on the intact human uterus. 7. Obstet. Gynaec. Brit. Emp. 51, 181.

Reynolds, S. R. M. (1949) Physiology of the uterus. Hoeber, New York. 